\title{
Correction to: Stability of personality traits over a five-year period in Swedish patients with schizophrenia spectrum disorder and nonpsychotic individuals: a study using the Swedish universities scales of personality
}

Tomas Fagerberg $^{1 *}$, Erik Söderman ${ }^{1}$, J. Petter Gustavsson ${ }^{2}$, Ingrid Agartz ${ }^{1,3,4}$ and Erik G. Jönsson ${ }^{1,3}$

Correction to: BMC Psychiatry

https://doi.org/10.1186/s12888-018-1617-y

After publication of the original article [1], it was brought to our attention that some of the numbers in Table 3 were incorrectly reported due to data entry errors. The corrected Table 3 can be found below - modified values are marked with bold. We apologize for the inconvenience this may have caused.

\footnotetext{
Author details

${ }^{1}$ Human Brain Informatics (HUBIN), Department of Clinical Neuroscience, Centre for Psychiatric Research, Psychiatry Section, Karolinska Institutet and Hospital, Stockholm, Sweden. ${ }^{2}$ Division of Psychology, Department of Clinical Neuroscience, Karolinska Institutet, Stockholm, Sweden. ${ }^{3}$ NORMENT, KG Jebsen Centre for Psychosis Research, Institute of Clinical Medicine, Psychiatry Section, University of Oslo, Oslo, Norway. ${ }^{4}$ Department of Psychiatric Research, Diakonhjemmet Hospital, Oslo, Norway.
}

Received: 19 March 2019 Accepted: 19 March 2019

Published online: 08 April 2019

\section{Reference}

1. Fagerberg, et al. Stability of personality traits over a five-year period in Swedish patients with schizophrenia spectrum disorder and nonpsychotic individuals: a study using the Swedish universities scales of personality. BMC Psychiatry. 2018;18:54. https://doi.org/10.1186/s12888-018-1617-y.

\footnotetext{
* Correspondence: Tomas.Fagerberg@ki.se

${ }^{1}$ Human Brain Informatics (HUBIN), Department of Clinical Neuroscience, Centre for Psychiatric Research, Psychiatry Section, Karolinska Institutet and Hospital, Stockholm, Sweden

Full list of author information is available at the end of the article
}

(c) The Author(s). 2019 Open Access This article is distributed under the terms of the Creative Commons Attribution 4.0 International License (http://creativecommons.org/licenses/by/4.0/), which permits unrestricted use, distribution, and reproduction in any medium, provided you give appropriate credit to the original author(s) and the source, provide a link to the Creative Commons license, and indicate if changes were made. The Creative Commons Public Domain Dedication waiver (http://creativecommons.org/publicdomain/zero/1.0/) applies to the data made available in this article, unless otherwise stated. 


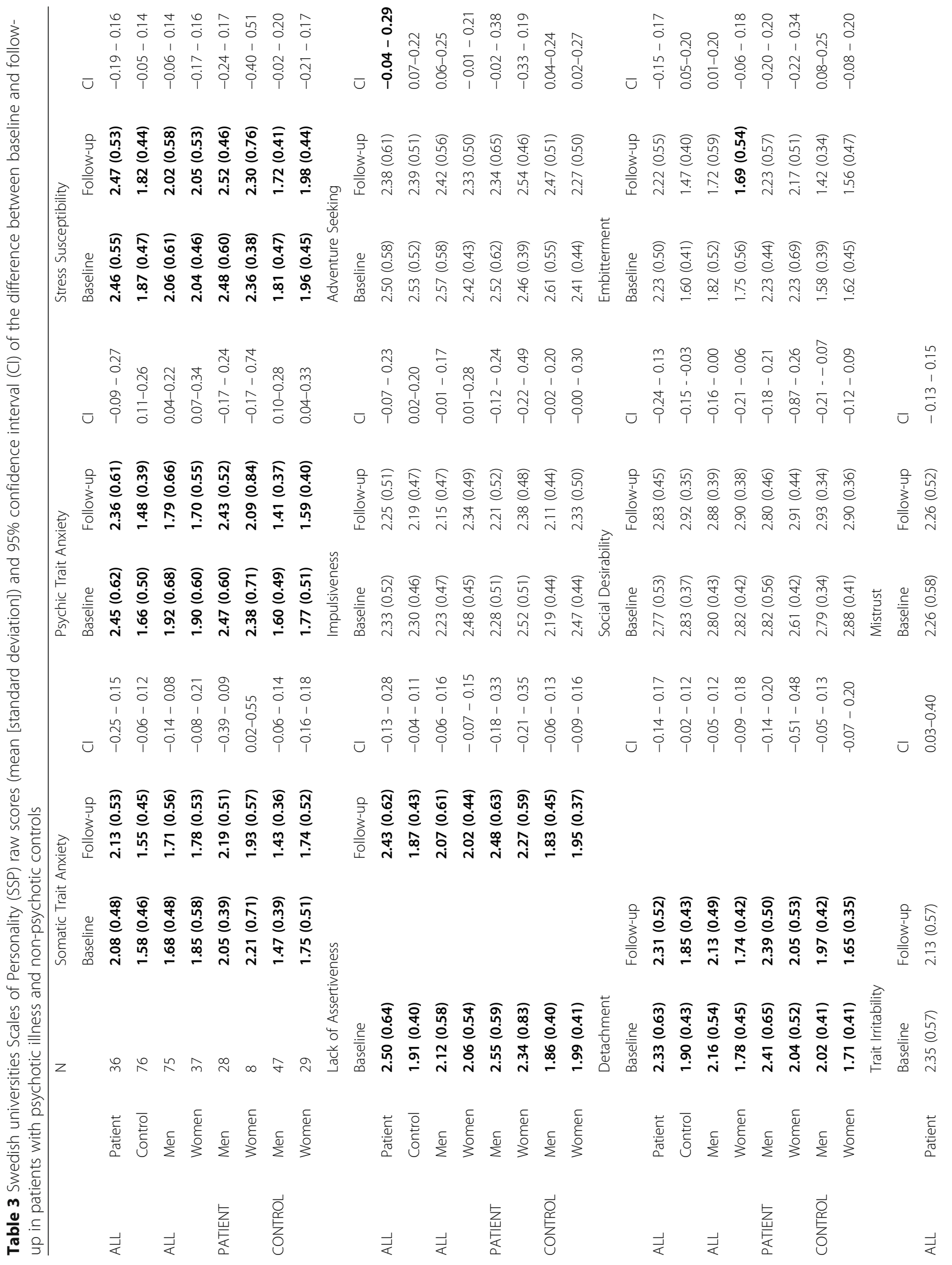




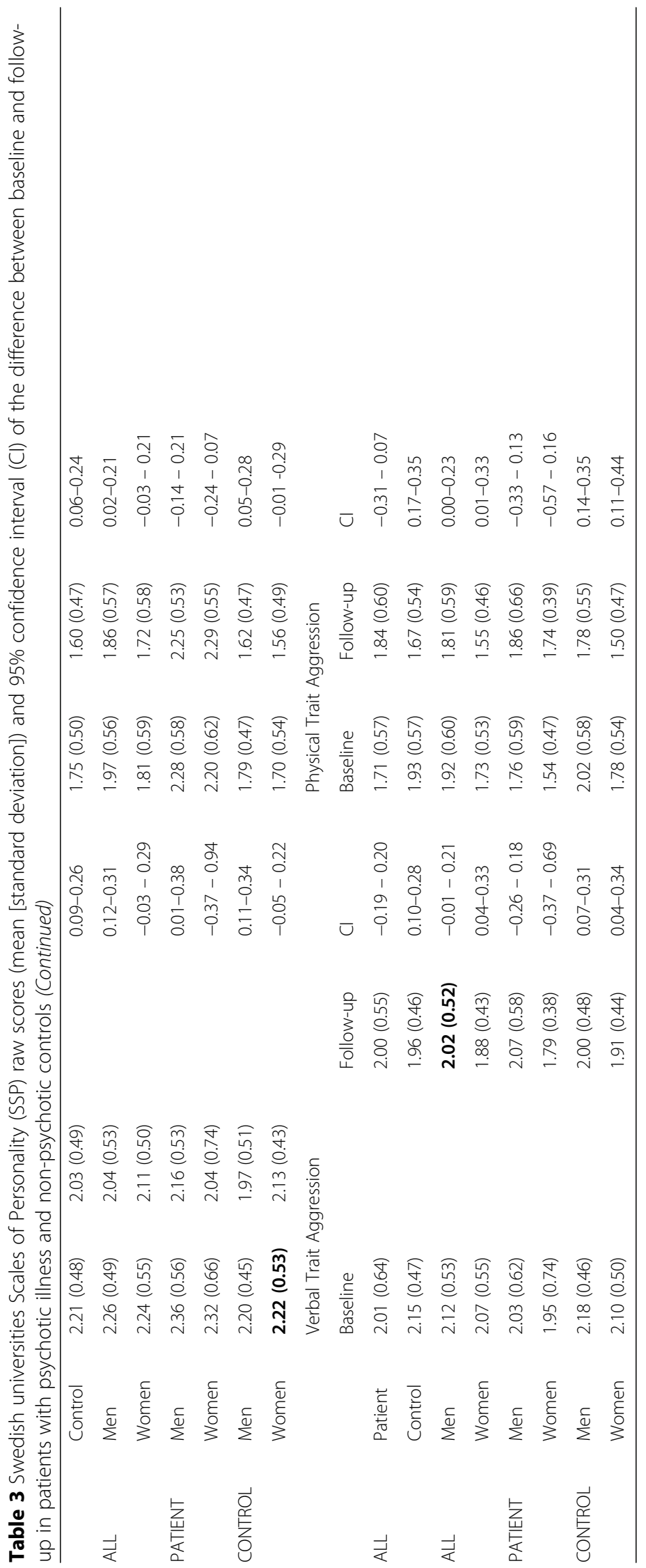

